\title{
Physiological Requirements to Perform the Glittre Activities of Daily Living Test by Subjects With Mild-to-Severe COPD
}

\author{
Gérson F Souza PT PhD, Graciane L Moreira PT PhD, Andréa Tufanin PT MSc, \\ Mariana R Gazzotti PT PhD, Antonio A Castro PT PhD, José R Jardim MD, and \\ Oliver A Nascimento MD
}

\begin{abstract}
BACKGROUND: The Glittre activities of daily living (ADL) test is supposed to evaluate the functional capacity of COPD patients. The physiological requirements of the test and the time taken to perform it by COPD patients in different disease stages are not well known. The objective of this work was to compare the metabolic, ventilatory, and cardiac requirements and the time taken to carry out the Glittre ADL test by COPD subjects with mild, moderate, and severe disease. METHODS: Spirometry, Medical Research Council questionnaire, cardiopulmonary exercise test, and 2 Glittre ADL tests were evaluated in 62 COPD subjects. Oxygen uptake $\left(\dot{\mathrm{V}}_{\mathrm{O}_{2}}\right)$, carbon dioxide production, pulmonary ventilation, breathing frequency, heart rate, $\mathrm{S}_{\mathrm{pO}_{2}}$, and dyspnea were analyzed before and at the end of the tests. Maximum voluntary ventilation, Glittre peak $\dot{\mathrm{V}}_{\mathrm{O}_{2}}$ /cardiopulmonary exercise test (CPET) peak $\dot{\mathrm{V}}_{\mathrm{O}_{2}}$, Glittre $\dot{\mathrm{V}}_{\mathrm{E}}$ /maximum voluntary ventilation, and Glittre peak heart rate/CPET peak heart rate ratios were calculated to analyze their reserves. RESULTS: Subjects carried out the Glittre ADL test with similar absolute metabolic, ventilatory, and cardiac requirements. Ventilatory reserve decreased progressively from mild to severe COPD subjects $(P<.001$ for Global Initiative for Chronic Obstructive Lung Disease [GOLD] 1 vs GOLD $2, P<.001$ for GOLD 1 vs GOLD 3, and $P<.001$ for GOLD 2 vs GOLD 3). Severe subjects with COPD presented a significantly lower metabolic reserve than the mild and moderate subjects $(P=.006$ and $P=.043$, respectively) and significantly lower Glittre peak heart rate/CPET peak heart rate than mild subjects $(P=.01)$. Time taken to carry out the Glittre ADL test was similar among the groups $(P=.82$ for GOLD 1 vs GOLD $2, P=.19$ for GOLD 1 vs GOLD 3 , and $P=.45$ for GOLD 2 vs GOLD 3). CONCLUSIONS: As the degree of air-flow obstruction progresses, the COPD subjects present significant lower ventilatory reserve to perform the Glittre ADL test. In addition, metabolic and cardiac reserves may differentiate the severe subjects. These variables may be better measures to differentiate functional performance than Glittre ADL time. Key words: activity of daily living; COPD; exercise test; functional capacity; outcome assessment; disability evaluation. [Respir Care 2017;62(8):1049-1057. (c) 2017 Daedalus Enterprises]
\end{abstract}

\section{Introduction}

Patients with COPD experience a decline in functional capacity, ${ }^{1}$ and in recent years, several studies have shown

\footnotetext{
Dr Souza, Dr Moreira, Ms Tufanin, Dr Gazzotti, and Dr Castro are affiliated with the Pulmonary Rehabilitation Center, Federal University of São Paulo, São Paulo, Brazil. Dr Castro is also affiliated with the Federal University of Pampa, Rio Grande do Sul, Brazil. Drs Jardim and Nascimento are affiliated with the Respiratory Division, Pulmonary Rehabilitation Center, Federal University of São Paulo, São Paulo, Brazil.

This study was performed with financial support from the Coordenação de Aperfeiçoamento de Pessoal de Nível Superior (CAPES, Brazil). The authors have disclosed no conflicts of interest.
}

that limitation of functional capacity is a better predictor of disability and mortality in COPD subjects than air-flow limitation. ${ }^{2-4}$

Functional capacity of COPD patients is usually evaluated by self-reported questionnaires and performance-based tests. ${ }^{5}$ However, self-reported questionnaires can be influenced by psychological factors, cognitive alterations, or

\footnotetext{
Correspondence: José R Jardim MD, Respiratory Division (Pneumologia), Federal University of São Paulo, Rua Botucatu, $740-3^{\circ}$ andar, São Paulo/SP CEP 04023-062, Brazil. E-mail: jardimpneumo@gmail.com.
}

DOI: $10.4187 /$ respcare. 05113 
adoption of a sedentary lifestyle, ${ }^{6}$ and they are often subject to recall bias, which can lead the patient to report a level of functional capacity that does not provide an accurate estimate of free-living energy expenditure. ${ }^{7,8}$

The 6-min walk test (6MWT) is one of the most frequently used field performance-based tests. ${ }^{9}$ Previous studies have shown a significant correlation between distance walked and the quantified physical activities of daily life in subjects with COPD. ${ }^{10-12}$ However, this test only evaluates the capacity of an individual to move, and it ignores activities carried out with the arms in the execution of many activities of daily living (ADLs). Furthermore, it is known that activities performed with the unsupported upper limbs can cause dyspnea in COPD patients due to competitive recruitment of muscle groups for either respiration or arm works. ${ }^{13}$ Tests that also include arm movements should be considered as alternative tests for this population. ${ }^{14,15}$

Skumlien et $\mathrm{al}^{16}$ proposed a test designed to evaluate the functional capacity of COPD patients, which is known as the Glittre activities of daily living test (Glittre ADL test). The Glittre ADL Test includes activities based on Lareau et $\mathrm{al}^{17}$ and on the London Chest Activity of Daily Living Scale, ${ }^{18}$ which include walking and arm movements. The Glittre ADL test involves rising from a chair, lifting, carrying, and bending, activities that are designed to represent common activities in everyday life that are known to be troublesome for patients with COPD. ${ }^{5,16}$ The main outcome is the time taken to accomplish the 5 laps of the test. The inclusion of upper-extremity activities makes it more similar to daily activity limitations than a walking test alone. ${ }^{5}$ The physiological responses of subjects with COPD during the course of the Glittre ADL test have been evaluated, ${ }^{19,20}$ and it has been shown that the time course response is similar to that of the 6MWT.

However, so far there is no study that has evaluated the Glittre ADL test with COPD subjects with different functional stages. We hypothesized that the more severe the degree of air-flow obstruction of COPD subjects, the greater the proportional metabolic, ventilatory, and cardiac requirements and the longer the time taken to carry out the Glittre ADL test. Thus, the objective of this study was to evaluate the length of time and at what proportion of the maximal metabolic, ventilatory, and cardiac capacities COPD subjects with mild, moderate, and severe air-flow obstruction would carry out the Glittre ADL test in an attempt to discriminate the subjects' severity.

\section{Methods}

A cross-sectional study was carried out at the Pulmonary Rehabilitation Center of Escola Paulista de Medicina, Brazil. The study was approved by the institutional review board (registry number 0938/10). The COPD subjects were

\section{QUICK LOOK}

\section{Current knowledge}

The Glittre activities of daily living (ADL) test is a test designed to evaluate the functional capacity of COPD patients. Recent studies have assessed the physiological responses of COPD subjects during the course of the Glittre ADL test. However, the physiological requirements during the time required to perform the Glittre ADL test in COPD subjects with different functional stages have not been studied.

\section{What this paper contributes to our knowledge}

Our study showed that subjects with mild to severe COPD presented progressive reductions in ventilatory and metabolic reserves to perform the Glittre ADL test as the severity of the disease progressed. Furthermore, the ADL time may not be a good measure to differentiate functional performance among the different disease severities, but ventilatory, metabolic, and cardiac reserves could be a marker to differentiate COPD severity.

selected consecutively and signed an informed consent form.

\section{Inclusion Criteria}

Subjects diagnosed according to Global Initiative for Chronic Obstructive Lung Disease (GOLD) ${ }^{21}$ spirometric criteria, with no exacerbation in the previous 4 weeks, $>40 \mathrm{y}$ old, and not taking part in a pulmonary rehabilitation program in the last $2 \mathrm{y}$ were included.

\section{Exclusion Criteria}

Hypoxemic patients at rest $\left(\mathrm{S}_{\mathrm{pO}_{2}}<88 \%\right)$ and patients with unstable cardiovascular diseases or musculoskeletal, neurological, or rheumatological diseases that could limit them carrying out the physical tests were not included. The evaluation protocol was as follows. Data collection was carried out over the course of 3 visits. During the first visit, subjects' clinical characteristics and body mass index (BMI) were evaluated, and spirometry was performed. During the second visit, a maximal cardiopulmonary exercise test (CPET) was carried out on a treadmill. During the third visit, the Medical Research Council questionnaire was administered, and 2 Glittre ADL test were carried out according to the procedures set forth by Skumlien et al. ${ }^{16}$ The analyzed values were chosen from the test with the shorter time. 


\section{BMI Assessment}

BMI was obtained by dividing the subject's body weight in kilograms by the height in meters squared $\left(\mathrm{kg} / \mathrm{m}^{2}\right)$. A BMI of $<22 \mathrm{~kg} / \mathrm{m}^{2}$ was considered malnutrition, 22$27 \mathrm{~kg} / \mathrm{m}^{2}$ was considered eutrophic, and BMI $>27 \mathrm{~kg} / \mathrm{m}^{2}$ was considered overweight. ${ }^{22}$

\section{Spirometry}

The test was assessed according to American Thoracic Society standards ${ }^{23}$ with a portable ultrasound-based spirometer (EasyOne, ndd Medical Technologies, Andover, Massachusetts). Volume was checked daily. Predicted values were calculated according to the Third National Health and Nutrition Examination Survey. FEV 1 and FVC were calculated. COPD staging was classified according to GOLD 2007.21

\section{Glittre ADL Test}

The test, as described by Skumlien et al, ${ }^{16}$ started with the subjects seated on a chair. At a starting signal, they stood up and then walked $5 \mathrm{~m}$, crossed over an interposed 2-step staircase, and walked another $5 \mathrm{~m}$ up to a 2 -shelf fixture, which was adjusted individually to the shoulder and waist height of each subject. Three bags weighing $1 \mathrm{~kg}$ each positioned on the top shelf had to be moved one by one to the bottom shelf, down to the floor, back to the bottom shelf, and finally to the top shelf again. The subjects then walked back to the initial chair where they had started from, crossed over the 2-step stairs, sat down, and immediately started the next lap by rising again. The subjects were asked to complete 5 laps as quickly as possible, and the main outcome of the test is time to perform its 5 laps. They were allowed to rest if necessary but were told to resume activity as soon as they could. The chronometer was not stopped. The subjects carried a backpack containing $2.5 \mathrm{~kg}$ (women) or $5.0 \mathrm{~kg}$ (men). Each step of the stair was $17 \mathrm{~cm}$ high and $27 \mathrm{~cm}$ deep.

\section{Maximal CPET}

The test was performed on a treadmill (Q35 Controlled Impact, Cybex, Medway, Massachusetts) according to the Harbor protocol. ${ }^{24}$ The procedure started with the patient walking on the treadmill at a fixed speed, without any inclination for the first $3 \mathrm{~min}$, followed by a $1 \%$ inclination increment at the end of each following minute. The test was continuously monitored with electrocardiographic CM5, AVF, and V2 leads (EP-3 Dixtal, São Paulo, Brazil). Subjects were encouraged to continue the exercise until exhaustion, but it could be immediately interrupted in the case of limiting symptoms, such as dyspnea, fatigue and/or pain in the lower limbs, dizziness or discomfort, precordial pain, severe arrhythmia, no increase in systolic pressure, or an exaggerated hypertensive response (systolic arterial pressure $>260 \mathrm{~mm} \mathrm{Hg}$ or diastolic pressure $>120 \mathrm{~mm} \mathrm{Hg}$ ). The exercise test was carried out to evaluate at which proportion of the maximal metabolic and cardiac rates the Glittre ADL test was performed.

\section{Variables Obtained in the Exercise Tests}

Physiological responses during the CPET and Glittre ADL test were evaluated in a breath-by-breath mode using a portable device $\left(\mathrm{K}_{4} \mathrm{~b}^{2}\right.$, Cosmed, Rome, Italy). The subjects breathed through a silicon mask firmly adjusted to their faces. The following variables were evaluated during the tests and analyzed at the basal conditions and at the end of the tests: oxygen uptake $\left(\dot{\mathrm{V}}_{\mathrm{O}_{2}}\right)$, carbon dioxide production $\left(\dot{\mathrm{V}}_{\mathrm{CO}_{2}}\right)$, minute ventilation $\left(\dot{\mathrm{V}}_{\mathrm{E}}\right)$, breathing frequency, heart rate, oxygen pulse $\left(\dot{\mathrm{V}}_{\mathrm{O}_{2}}\right.$ /heart rate), $\mathrm{S}_{\mathrm{pO}_{2}}$ (measured with a model $920 \mathrm{M}$ pulse oximeter; Healthdyne Technologies, Marietta, Georgia), and dyspnea (Borg score). The Glittre peak $\dot{\mathrm{V}}_{\mathrm{O}_{2}}$ was considered as the highest value reached at the end of the Glittre ADL test, and the CPET peak $\dot{\mathrm{O}}_{\mathrm{O}_{2}}$ was considered as the highest value reached at the end of the CPET; Glittre peak $\dot{\mathrm{V}}_{\mathrm{O}_{2}}$ /CPET peak $\dot{\mathrm{V}}_{\mathrm{O}_{2}}$ was used to analyze the metabolic reserve. The Glittre peak $\dot{V}_{\mathrm{E}}$ was considered as the highest value reached at the end of the Glittre ADL test, and the maximum voluntary ventilation (MVV) was calculated as the product of $\mathrm{FEV}_{1} \times 37.5^{25}$; Glittre $\dot{\mathrm{V}}_{\mathrm{E}} / \mathrm{MVV}$ was used to analyze the ventilatory reserve. The Glittre peak heart rate was considered as the highest value reached at the end of the Glittre ADL test, and the CPET peak HR was considered as the highest value at the end of the CPET; Glittre peak heart rate/CPET peak heart rate was used to analyze the cardiac reserve.

\section{Statistical Analyses}

Sample size calculation was based on the study's primary aim, which was to compare the metabolic, ventilatory, and cardiac requirements for mild-to-severe COPD subjects to carry out the Glittre ADL test. We calculated our sample size according to the formula $\mathrm{E} / \mathrm{S}$, where $\mathrm{E}$ represents the expected effect or the minimum clinical difference, and $\mathrm{S}$ is the sample standard deviation. Since there are no energy outputs or ventilatory or cardiac values of normality for the Glittre ADL test and/or no expected minimum clinical difference for this scenario, we used for the calculation the mean difference values (final - initial) of these variables from a pilot sample in our laboratory to establish $\mathrm{E}$ and $\mathrm{S}$ values. An $\mathrm{E}$ value of $0.7 \mathrm{~L}$ and an $\mathrm{S}$ value of $0.2 \mathrm{~L}$ were found. Considering an $\alpha$ of .05 and a power of $80 \%, 17$ subjects were necessary in each one of the 3 groups: mild, moderate, and severe. ${ }^{26}$ The Shapiro- 
Table 1. General Characteristics of Subjects With COPD

\begin{tabular}{|c|c|c|c|c|c|c|c|}
\hline Variables & All & GOLD 1 & GOLD 2 & GOLD 3 & $\begin{array}{c}P \\
(\text { GOLD } 1 \text { vs } \\
\text { GOLD 2) }\end{array}$ & $\begin{array}{c}P \\
(\text { GOLD } 1 \text { vs } \\
\text { GOLD 3) }\end{array}$ & $\begin{array}{c}P \\
\text { (GOLD 2 vs } \\
\text { GOLD 3) }\end{array}$ \\
\hline Sex, $n(\%)$ & & & & & .38 & .38 & .38 \\
\hline Male & $40(64.5)$ & $15(75)$ & $12(54.5)$ & $13(65)$ & & & \\
\hline Female & $22(35.5)$ & $5(25)$ & $10(45.5)$ & $7(35)$ & & & \\
\hline Age, mean \pm SD y & $66.2 \pm 8.2$ & $68.3 \pm 9.8$ & $65.3 \pm 6.7$ & $64.9 \pm 7.9$ & .47 & .39 & .98 \\
\hline $\mathrm{BMI}$, mean $\pm \mathrm{SD} \mathrm{kg} / \mathrm{m}^{2}$ & $26.2 \pm 4.2$ & $26.6 \pm 4.9$ & $27 \pm 3.9$ & $24.8 \pm 3,7$ & .95 & .37 & .21 \\
\hline $\mathrm{MRC}$, mean $\pm \mathrm{SD}$ & $1.7 \pm 0.7$ & $1.2 \pm 0.4$ & $1.7 \pm 0.6$ & $2.2 \pm 0.7$ & .031 & $<.001$ & .02 \\
\hline $\mathrm{MVV}$, mean $\pm \mathrm{SD} \mathrm{L}$ & $63.8 \pm 24.1$ & $87 \pm 20.5$ & $62 \pm 16.7$ & $42.6 \pm 9.7$ & $<.001$ & $<.001$ & .001 \\
\hline $\mathrm{FEV}_{1} / \mathrm{FVC}$ & $0.53 \pm 0.11$ & $0.64 \pm 0.06$ & $0.53 \pm 0.08$ & $0.42 \pm 0.05$ & $<.001$ & $<.001$ & $<.001$ \\
\hline $\mathrm{FEV}_{1}$, mean $\pm \mathrm{SD} \%$ predicted & $65.4 \pm 20.1$ & $89.4 \pm 9.5$ & $63.6 \pm 8.4$ & $43.4 \pm 3,7$ & $<.001$ & $<.001$ & $<.001$ \\
\hline $\mathrm{FVC}$, mean $\pm \mathrm{SD} \%$ predicted & $94.2 \pm 15.5$ & $105.4 \pm 12.9$ & $95.7 \pm 12.9$ & $81.2 \pm 10.1$ & .032 & $<.001$ & $<.001$ \\
\hline Peak $\dot{\mathrm{V}}_{\mathrm{O}_{2}}$, mean $\pm \mathrm{SD} \% \mathrm{~mL} / \mathrm{min}$ & $1,424.9 \pm 451.4$ & $1,542.0 \pm 465.5$ & $1,473.3 \pm 543.4$ & $1,254.8 \pm 252.1$ & .87 & .11 & .25 \\
\hline \multicolumn{8}{|c|}{$\begin{array}{l}n=62 . \\
\text { GOLD = Global Initiative for Chronic Obstructive Lung Disease } \\
\text { BMI = body mass index } \\
\text { MRC = Medical Research Council } \\
\mathrm{MVV}=\text { maximal voluntary ventilation } \\
\dot{\mathrm{V}}_{\mathrm{O}_{2}}=\text { oxygen uptake in the cardiopulmonary exercise test }\end{array}$} \\
\hline
\end{tabular}

Wilk normality test showed a normal distribution of the data, allowing for the application of parametric tests using the means and SD values. The chi-square test was used to compare the proportions of men and women among the groups. A Pearson correlation was used to evaluate MVV versus ADL time. An analysis of variance was also used to compare the differences among the anthropometric variables, pulmonary function, and physiological variables obtained in the exercise tests. The Bonferroni correction was used to locate the difference when the analysis of variance results were significant $(P<.05)$.

\section{Results}

From 70 subjects selected to participate in this study, 8 subjects were excluded as follows: 3 showed signs of ischemia in the incremental exercise test, 3 exacerbated during the evaluation period, and 2 had asthma. Thus, 62 COPD subjects concluded the study: 20 were in the mild stage, 22 were in the moderate stage, and 20 were in the severe stage. The groups included similar proportions of men and women $(P=.38)$ with similar age $(P=.47$ for GOLD 1 vs GOLD $2, P=.39$ for GOLD 1 vs GOLD 3 , and $P=.98$ for GOLD 2 vs GOLD 3$)$ and BMI $(P=.95$ for GOLD 1 vs GOLD $2, P=.37$ for GOLD 1 vs GOLD 3, and $P=.21$ for GOLD 2 vs GOLD 3) means. As expected, there were statistically significant differences among the groups in Medical Research Council dyspnea score $(P=.031$ for GOLD 1 vs GOLD 2, $P<.001$ for GOLD 1 vs GOLD 3, and $P=.02$ for GOLD 2 vs GOLD 3), MVV $(P<.001$ for GOLD 1 vs GOLD 2, $P<.001$ for GOLD 1 vs GOLD 3 , and $P=.001$ for GOLD 2 vs GOLD 3), and spirometric variables (Table 1). There were no significant differences in the peak $\dot{\mathrm{V}}_{\mathrm{O}_{2}}(P=.87$ for GOLD 1 vs GOLD 2, $P=.11$ for GOLD 1 vs GOLD 3, and $P=.25$ for GOLD 2 vs GOLD 3) obtained in the CPET among the 3 groups (Table 1). The comorbidities found comprised the most common diseases in COPD: cardiovascular diseases, including systemic arterial hypertension, previous myocardial infarction, heart failure, and coronary ischemia, 66\%; diabetes, $27 \%$; osteoporosis, $15 \%$; previous neoplasia, $15 \%$; asthma, $17 \%$.

\section{Analysis of the Glittre ADL Test Requirements}

There were no differences in the basal values of the physiological variables among the 3 disease stages (Table 2 ). The time taken to carry out the Glittre ADL test (Glittre ADL time) was not statistically different among the 3 groups of subjects (mild subjects, $4.5 \pm 0.9 \mathrm{~min}$; moderate, $4.8 \pm 1.1 \mathrm{~min}$; severe, $5.2 \pm 1.7 \mathrm{~min}, P=.82$ for GOLD 1 vs GOLD 2, $P=.19$ for GOLD 1 vs GOLD 3, and $P=.45$ for GOLD 2 vs GOLD 3), although there was a numerical tendency to increased times as the disease increased in severity (Fig. 1).

Table 3 shows that the energy expenditure (Glittre $\left.\dot{\mathrm{V}}_{\mathrm{O}_{2}}\right)$ required by the subjects in different stages of COPD to carry out the Glittre ADL test was similar $(P=.94$ for GOLD 1 vs GOLD 2, $P=.95$ for GOLD 1 vs GOLD 3, and $P=.81$ for GOLD 2 vs GOLD 3). However, the Glittre $\dot{\mathrm{V}}_{\mathrm{O}_{2}}$ analyzed in relation to the peak $\dot{\mathrm{V}}_{\mathrm{O}_{2}}$ obtained in the CPET was significantly higher in the severe COPD subjects than in the mild and moderate COPD subjects ( $P=.006$ and $P=.043$, respectively), providing evidence 
Physiologic Requirements of Glittre ADL Test in COPD

Table 2. Physiologic Variables at Baseline of the Glittre Activities of Daily Living Test

\begin{tabular}{|c|c|c|c|c|c|c|c|}
\hline Variables & $\begin{array}{c}\text { All } \\
(n=62)\end{array}$ & $\begin{array}{l}\text { GOLD } 1 \\
(n=20)\end{array}$ & $\begin{array}{l}\text { GOLD } 2 \\
(n=22)\end{array}$ & $\begin{array}{l}\text { GOLD } 3 \\
(n=20)\end{array}$ & $\begin{array}{c}P \\
(\text { GOLD } 1 \text { vs } \\
\text { GOLD 2) }\end{array}$ & $\begin{array}{c}P \\
(\text { GOLD } 1 \text { vs } \\
\text { GOLD 3) }\end{array}$ & $\begin{array}{c}P \\
\text { (GOLD 2 vs } \\
\text { GOLD 3) }\end{array}$ \\
\hline Heart rate, beats/min & $77.9 \pm 12.7$ & $75.1 \pm 15.2$ & $79.5 \pm 10.5$ & $78.9 \pm 12.4$ & .52 & .63 & .99 \\
\hline$\dot{\mathrm{V}}_{\mathrm{O}_{2}} /$ heart rate, $\mathrm{mL} /$ beat & $3.2 \pm 1.1$ & $3.3 \pm 1.3$ & $3.0 \pm 0.8$ & $3.4 \pm 1.1$ & .77 & .77 & .35 \\
\hline Breathing frequency, breaths/min & $19.1 \pm 4.0$ & $18.6 \pm 4.6$ & $19.1 \pm 4.2$ & $19.6 \pm 3.4$ & .87 & .70 & .94 \\
\hline$\dot{\mathrm{V}}_{\mathrm{E}}, \mathrm{L} / \mathrm{min}$ & $11.3 \pm 3.6$ & $10.4 \pm 3.8$ & $11.3 \pm 3.2$ & $12.1 \pm 3.7$ & .72 & .33 & .77 \\
\hline $\mathrm{S}_{\mathrm{pO}_{2}}, \%$ & $95.1 \pm 2.0$ & $95.9 \pm 1.5$ & $95.2 \pm 1.7$ & $94.3 \pm 2.5$ & .51 & .031 & .28 \\
\hline$\dot{\mathrm{V}}_{\mathrm{O}_{2}}, \mathrm{~mL} / \mathrm{min}$ & $251.4 \pm 74.4$ & $241.9 \pm 79.9$ & $242.9 \pm 62.1$ & $270.3 \pm 81.1$ & .99 & .45 & .46 \\
\hline$\dot{\mathrm{V}}_{\mathrm{CO}_{2}}, \mathrm{~mL} / \mathrm{min}$ & $232.8 \pm 79.4$ & $230.1 \pm 81.3$ & $230.4 \pm 83.0$ & $238.1 \pm 77.3$ & $>.99$ & .95 & .95 \\
\hline Dyspnea (Borg scale) & $0.3 \pm 0.8$ & $0.2 \pm 0.7$ & $0.4 \pm 1.2$ & $0.2 \pm 0.5$ & .49 & .93 & .72 \\
\hline \multicolumn{8}{|c|}{$\begin{array}{l}\text { Results are mean } \pm \mathrm{SD} \text {. } \\
\mathrm{GOLD}=\text { Global Initiative for Chronic Obstructive Lung Disease } \\
\dot{\mathrm{V}}_{\mathrm{O}_{2}} \text { /heart rate }=\text { oxygen pulse } \\
\dot{\mathrm{V}}_{\mathrm{E}}=\text { minute pulmonary volume } \\
\dot{\mathrm{V}}_{\mathrm{O}_{2}}=\text { oxygen uptake } \\
\dot{\mathrm{V}}_{\mathrm{CO}_{2}}=\text { carbon dioxide production }\end{array}$} \\
\hline
\end{tabular}

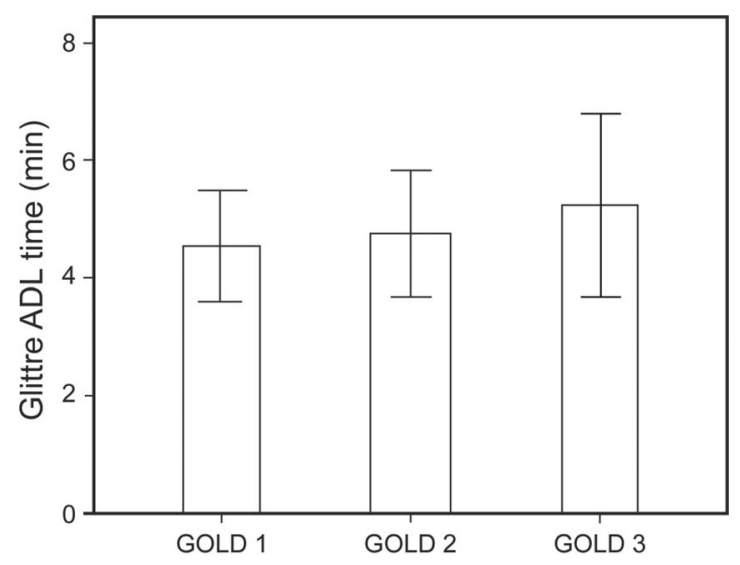

Fig. 1. Time taken to perform the Glittre activities of daily living (Glittre ADL) test by severity of COPD obstruction according to Global Initiative for Chronic Obstructive Lung Disease (GOLD) grades. No significant difference was seen among the 3 groups ( $P=.82$ for GOLD 1 vs GOLD 2; $P=.19$ for GOLD 1 vs GOLD 3; and $=.45$ for GOLD 2 vs GOLD 3).

of a lower metabolic reserve (Glittre peak $\dot{\mathrm{V}}_{\mathrm{O}_{2}}$ /CPET peak $\dot{\mathrm{V}}_{\mathrm{O}_{2}}$ ) in subjects with severe air-flow obstruction.

The subjects in the different stages of COPD carried out the Glittre ADL test with similar ventilatory requirements (Glittre $\dot{\mathrm{V}}_{\mathrm{E}}, P=.84$ for GOLD 1 vs GOLD 2, $P=.97$ for GOLD 1 vs GOLD 3, and $P=.70$ for GOLD 2 vs GOLD 3). However, when the Glittre $\dot{V}_{\mathrm{E}}$ for carrying out the test was related to MVV, the severe COPD subjects presented a significantly lower ventilatory reserve $\left(\right.$ Glittre $\left.\dot{\mathrm{V}}_{\mathrm{E}} / \mathrm{MVV}\right)$ than the mild $(P<.001)$ and moderate $(P<.001)$ COPD subjects (Table 3 ). In addition, the moderate COPD subjects showed a significantly lower Glittre $\dot{\mathrm{V}}_{\mathrm{E}} / \mathrm{MVV}$ than the mild COPD subjects did $(P<.001)$. Just the severe subject group presented ventilatory limitation with a Glittre $\dot{\mathrm{V}}_{\mathrm{E}} / \mathrm{MMV}$ ratio $>0.8$ (Table 3 ). There was a moderate correlation between Glittre ADL time and MVV $(r=-0.41$, $P=.001)$.

The severe COPD subjects showed significantly lower cardiac reserve (Glittre peak heart rate/peak heart rate) than the mild subjects $(P=.01)$ at the end of the Glittre ADL test (Table 3 ). The severe COPD subjects also reported a significantly greater sensation of dyspnea $(P=.001$ for GOLD 1 vs GOLD 3, $P=.02$ for GOLD 2 vs GOLD $3)$ and displayed a significant decrease in $\mathrm{S}_{\mathrm{pO}_{2}}(P<.001$ for GOLD 1 vs GOLD 3, $P=.002$ for GOLD 2 vs GOLD 3 ) at the end of the Glittre ADL test compared with the subjects in the other stages (Table 3 ).

\section{Discussion}

The present study showed that when mild, moderate, and severe COPD subjects performed the Glittre ADL test, the only parameter that could differentiate the 3 groups was the significant and progressively lower ventilatory reserve as the disease increased in severity. This finding may explain the significantly increased dyspnea in the severe COPD subjects compared with the moderate and mild subjects. These 2 findings point out that ventilation is the main limitation for COPD patients when performing the Glittre ADL test, which attempts to reproduce the daily activities that COPD patients face in their day-to-day life. It is possible that metabolic and cardiac function might also have played a role in the COPD subjects' limitation, but there was not a progressive decrease in their reserves, as we saw with the ventilatory reserve. Despite Skuliem et $\mathrm{al}^{16}$ having proposed time as the primary outcome of the Glittre ADL test, we found no significant difference in the time taken to carry out the test among the 3 groups.

Analysis of metabolic, ventilatory, and cardiovascular variables is normally used to express the performance of a 
Physiologic Requirements of Glittre ADL Test in COPD

Table 3. Physiologic Variables at Peak of the Glittre Activities of Daily Living Test

\begin{tabular}{|c|c|c|c|c|c|c|c|}
\hline Variables & $\begin{array}{c}\text { All } \\
(N=62)\end{array}$ & $\begin{array}{l}\text { GOLD } 1 \\
(n=20)\end{array}$ & $\begin{array}{l}\text { GOLD } 2 \\
(n=22)\end{array}$ & $\begin{array}{l}\text { GOLD } 3 \\
(n=20)\end{array}$ & $\begin{array}{c}P \\
(\text { GOLD } 1 \text { vs } \\
\text { GOLD 2) }\end{array}$ & $\begin{array}{c}P \\
\text { (GOLD 1 vs } \\
\text { GOLD 3) }\end{array}$ & $\begin{array}{c}P \\
\text { (GOLD 2 vs } \\
\text { GOLD 3) }\end{array}$ \\
\hline Glittre peak heart rate, beats/min & $111.9 \pm 15.9$ & $107.1 \pm 17.6$ & $113.9 \pm 14.4$ & $114.7 \pm 15.3$ & .35 & .29 & .98 \\
\hline $\begin{array}{l}\text { Glittre peak heart rate/CPET peak } \\
\text { heart rate, } \%\end{array}$ & $87.4 \pm 12.7$ & $81.4 \pm 11.0$ & $89.5 \pm 13.1$ & $92.9 \pm 11.4$ & .08 & .01 & .65 \\
\hline$\dot{\mathrm{V}}_{\mathrm{O}_{2}}$ /heart rate, $\mathrm{mL} /$ beat & $11.0 \pm 2.9$ & $11.4 \pm 2.6$ & $11.0 \pm 3.3$ & $10.6 \pm 3.0$ & .83 & .52 & .85 \\
\hline Breathing frequency, breaths/min & $30.4 \pm 5.9$ & $29.5 \pm 7.6$ & $31.0 \pm 5.2$ & $30.6 \pm 4.9$ & .73 & .88 & .96 \\
\hline Glittre peak $\dot{\mathrm{V}}_{\mathrm{E}}, \mathrm{L} / \mathrm{min}$ & $39.4 \pm 9.8$ & $39.0 \pm 8.5$ & $40.8 \pm 11.6$ & $38.3 \pm 9.2$ & .84 & .97 & .70 \\
\hline Glittre peak $\dot{\mathrm{V}}_{\mathrm{E}} / \mathrm{MVV}$ & $0.69 \pm 0.25$ & $0.46 \pm 0.11$ & $0.68 \pm 0.18$ & $0.92 \pm 0.20$ & $<.001$ & $<.001$ & $<.001$ \\
\hline $\mathrm{S}_{\mathrm{pO}_{2}}, \%$ & $90.4 \pm 4.9$ & $93.2 \pm 3.4$ & $91.3 \pm 3.9$ & $86.7 \pm 4.9$ & .29 & $<.001$ & .002 \\
\hline Glittre peak $\dot{\mathrm{V}}_{\mathrm{O}_{2}}, \mathrm{~mL} / \mathrm{min}$ & $1,223.6 \pm 350.4$ & $1,221.6 \pm 323.9$ & $1,256.7 \pm 405.8$ & $1,189.0 \pm 323.7$ & .94 & .95 & .81 \\
\hline Glittre peak $\dot{\mathrm{V}}_{\mathrm{O}_{2}} /$ CPET peak $\dot{\mathrm{V}}_{\mathrm{O}_{2}}$ & $0.88 \pm 0.2$ & $0.81 \pm 0.1$ & $0.88 \pm 0.2$ & $0.96 \pm 0.2$ & .71 & .006 & .043 \\
\hline Glittre peak $\dot{\mathrm{V}}_{\mathrm{CO}_{2}}, \mathrm{~mL} / \mathrm{min}$ & $1,022.6 \pm 295.2$ & $1,087.0 \pm 303.0$ & $1,003.9 \pm 338.4$ & $978.7 \pm 234.0$ & .64 & .48 & .96 \\
\hline Dyspnea (Borg scale) & $3.0 \pm 2.4$ & $1.9 \pm 2.3$ & $2.5 \pm 2.2$ & $4.5 \pm 2.2$ & .63 & .001 & .02 \\
\hline $\begin{array}{l}\text { Results are mean } \pm \text { SD. } \\
\text { GOLD = Global Initiative for Chronic Obstru } \\
\text { CPET = cardiopulmonary exercise test } \\
\dot{V}_{\mathrm{O}_{2}} \text { heart rate = oxygen pulse } \\
\dot{\mathrm{V}}_{\mathrm{E}}=\text { minute pulmonary volume } \\
\mathrm{MVV}=\text { maximum ventilatory ventilation } \\
\dot{\mathrm{V}}_{\mathrm{O}_{2}}=\text { oxygen uptake } \\
\dot{\mathrm{V}}_{\mathrm{CO}_{2}}=\text { carbon dioxide production }\end{array}$ & ctive Lung Disease & & & & & & \\
\hline
\end{tabular}

subject or a group of subjects during a physical test, since they may indicate the importance of each component in the exercise performance limitation. We analyzed these variables in COPD subjects with mild, moderate, and severe disease during their performance of the Glittre ADL test in an attempt to discriminate their severity by the test. We found no difference in absolute values in metabolic, ventilatory, and cardiac demands, required to carry out the Glittre ADL test among the 3 groups of subjects, indicating that the effort performed to carry out the test was similar in the different severity stages of the disease, despite a large variability of results in each disease group. It has been shown that the $\mathrm{FEV}_{1}$ is not strongly correlated to either physical activity in daily life or the walking distance in the 6MWT. 12,27

Because there were no differences in the in peak $\dot{\mathrm{V}}_{\mathrm{O}_{2}}$ during the CPET test among groups of COPD severity, it could be anticipated that the values would also not differ during Glittre ADL test. However, when the variables are looked at as a proportion of their maximal values, we observed that there was a significant decrease in the reserves of the 3 variables, but the ventilatory reserve was the only one that steadily decreased as severity of the disease increased. We believe that the ventilatory reserve decrease was the mechanism responsible for the increased dyspnea reported by the severe group of subjects at the end of the Glittre ADL test. Pitta et $\mathrm{a}^{28}$ had already shown that ventilation as expressed by MVV is a parameter that may best associate with total energy expenditure in COPD subjects when they took into consideration the number of steps taken per day and time taken to carry out moderate and vigorous activities. We also found a significant moderate correlation between Glittre ADL time and MVV, which supports the idea that ventilatory capacity plays a role in limiting the accomplishment of the Glittre ADL test. The metabolic reserve required to carry out the Glittre ADL test exhibited a somewhat similar behavior to what was observed with the ventilatory reserve. Although subjects in the different stages of the disease presented similar absolute $\dot{\mathrm{V}}_{\mathrm{O}_{2}}$ values to perform the Glittre ADL test, contrary to the decreasing ventilatory reserve seen with increasing disease severity, only the severe subjects presented a significantly lower metabolic reserve (Glittre $\dot{\mathrm{V}}_{\mathrm{O}_{2}}$ /CPET peak $\dot{\mathrm{V}}_{\mathrm{O}_{2}}$ ) compared with the mild and moderate COPD subjects. The lower metabolic reserve of severe COPD subjects may be another limitation factor for the severe patients to carry out their ADLs in real life. Vaes et $\mathrm{al}^{29}$ evaluated energy expenditure in moderate, severe, and very severe COPD subjects while carrying out 5 ADLs, and they showed, as in the present study, that the ventilatory and metabolic reserves decreased with the increase in severity of the disease. Castro et $\mathrm{al}^{30}$ also did not find any difference in the absolute $\dot{\mathrm{V}}_{\mathrm{O}_{2}}$ and $\dot{\mathrm{V}}_{\mathrm{E}}$ values measured in mild-to-very severe COPD subjects when carrying out a large number of ADLs. These authors also found that the only parameters that could differentiate their groups were $\dot{\mathrm{V}}_{\mathrm{E}} / \mathrm{MVV}$ and $\dot{\mathrm{V}}_{\mathrm{O}_{2}}$ /maximum $\dot{\mathrm{V}}_{\mathrm{O}_{2}}$ ratios, both decreasing from mild to very severe subjects. Thus, the results of Vaes et al, ${ }^{29}$ Castro et al, ${ }^{30}$ and our own work seem to point in the same direction, that the progressive worsening 
of dyspnea reported by COPD subjects when carrying out their ADLs is associated with the decrease in ventilatory and metabolic reserves as the disease severity increases. We also observed reduced cardiac reserve in the severe subject group in relation to the mild subject group. Cardiovascular disease is a major comorbidity in COPD and probably the most frequent and most important disease coexisting with COPD. ${ }^{21}$ Our results seem to indicate that ventilatory reserve is an important functionality-limiting factor across all stages of the disease, whereas metabolic and cardiac factors may play an associated role in the more severe stages of the disease.

We observed that severe subjects showed a significantly lower peripheral oxygen desaturation at the end of the Glittre ADL test than subjects with mild and moderate disease. Similar results were found by Cutaia et al, ${ }^{31}$ who showed a decreased $\mathrm{S}_{\mathrm{pO}_{2}}$ directly associated with severity of the disease in COPD subjects during daily activities. Andrianopoulos et al ${ }^{32}$ showed a relationship between impaired lung function and oxygen desaturation during the exercise in non-hypoxic COPD subjects. COPD subjects with an $\mathrm{FEV}_{1}<45 \%$ of predicted generally present oxygen desaturation during the $6 \mathrm{MWT}$, which is in agreement with our results. Arterial desaturation is associated with low ventilation-perfusion ratios.

The time measured to complete the Glittre ADL test was described as the primary outcome of the Glittre ADL test by Skumlien et al, ${ }^{16}$ but in their original study, they did not evaluate subjects with different disease severities. In our study, we evaluated the ADL time in mild-to-severe COPD subjects but did not find a significant difference among the 3 groups, despite a tendency to a longer time in moderate subjects compared with mild subjects and in the severe subjects compared with moderate subjects. We did not study very severe subjects, but considering the increasing time from the mild to severe subjects, it is possible that the time to perform the Glittre ADL test could differentiate the very severe subjects from the mild or even moderate subjects. It is not easy to explain why there was not a difference in time for the performance of the test. However, we grouped the subjects by bronchial obstruction, whereas the COPD disease is a multisystemic disease, and each one of its components may account for different proportions of its activity limitation. Despite ventilatory limitation being most probably the main limiting factor, in some subjects, the cardiac component may play an important role, whereas in others, it could be a peripheral factor. Pitta et $\mathrm{a}^{28}$ also did not find a difference among COPD subjects in the moderate, severe, and very severe stages of the disease in terms of time taken to carry out vigorous activities demanding 6-9 metabolic equivalents.

We might consider a few limitations in our study. We did not compare COPD subjects with a healthy age-matched control group. Notwithstanding this, our aim was to assess the physiological requirements and the time spent to accomplish the Glittre ADL test in COPD subjects within 3 disease severity stages; therefore, the lack of a control group did not influence our outcomes. Another possible limitation was the exclusion of very severe COPD subjects. This exclusion was due to the fact that during a pilot study, all very severe subjects had tremendous difficulty accomplishing the CPET and the Glittre ADL test. We present only the basal and peak values obtained at the end of the Glittre ADL test of the physiological variables studied. Our objective was to compare the metabolic, ventilatory, and cardiac requirements in subjects with mild to moderate COPD at the end of performing the Glittre ADL test and not to study the behavior of such variables throughout the test. The behavior of such variables throughout the test has already been presented in the study by Tufanin et $\mathrm{al}^{19} \mathrm{~A}$ strength of our study is (1) to have evaluated a powerful calculated sample, (2) to have included a larger number of subjects than in the Karloh et $\mathrm{al}^{20}$ and Tufanin et $\mathrm{al}^{19}$ studies, and (3) to have evaluated the performance of COPD subjects with different degrees of disease.

Our results are similar to those presented by other authors who assessed the ventilatory and metabolic reserves of subjects accomplishing ADLs. The Glittre ADL test was developed for use in clinic practice, because it encompasses activities similar to very common activities of daily living. However, the ADL time that is considered the primary outcome of the test was not a good outcome to differentiate functional performance among the different disease severities, but the metabolic, ventilatory, and cardiac reserves could be a marker to differentiate COPD severity. However, these measurements are not readily available in the routine evaluation of COPD subjects and are not easily captured in clinical practice, because they are time-consuming, and specific equipment is necessary for gas analysis. Maybe these measurements could be restricted to research. Moreover, other tests have already been used to assess functionality in COPD subjects and are easier to perform. The 6MWT has been correlated with disease staging, health status, dyspnea at rest, maximum exercise capacity, and mortality. ${ }^{33,34}$ The shuttle test, despite less use than the 6MWT, also has the ability to measure physical capacity changes in COPD submitted to an intervention. ${ }^{35}$ In addition, unsupported upper-limb tests could also describe the functionality of COPD patients ${ }^{36}$ and could be taken alone or in conjunction with the 6MWT or shuttle test.

Thus, we conclude that as the degree of air-flow obstruction progresses, COPD subjects present significantly lower ventilatory reserve to perform the Glittre ADL test. In addition, the metabolic reserve to perform the Glittre ADL test was significantly lower in severe than in mild and moderate COPD subjects. It is possible that the cardiac reserve may also differentiate COPD patients by their 
severity. These variables may be better measures for differentiating functional performance among the different disease severities than ADL time.

\section{ACKNOWLEDGMENTS}

We thank the multidisciplinary team from the Pulmonary Rehabilitation Center, Federal University of São Paulo.

\section{REFERENCES}

1. Kapella MC, Larson JL, Covey MK, Alex CG. Functional performance in chronic obstructive pulmonary disease declines with time. Med Sci Sports Exerc 2011;43(2):218-224.

2. Fan VS, Ramsey SD, Make BJ, Martinez FJ. Physiologic variables and functional status independently predict COPD hospitalizations and emergency department visits in patients with severe COPD. COPD 2007;4(1):29-39.

3. Pitta F, Troosters T, Probst VS, Spruit MA, Decramer M, Gosselink R. Physical activity and hospitalization for exacerbation of COPD. Chest 2006;129(3):536-544.

4. Garcia-Aymerich J, Lange P, Benet M, Schnohr P, Antó JM. Regular physical activity reduces hospital admission and mortality in chronic obstructive pulmonary disease: a population based cohort study. Tho$\operatorname{rax} 2006 ; 61(9): 772-778$.

5. Dechman G, Scherer SA. Outcome measures in cardiopulmonary physical therapy: focus on the Glittre ADL-test for people with chronic obstructive pulmonary disease. Cardiopulm Phys Ther J 2008;19(4): 115-118.

6. Reardon JZ, Lareau SC, ZuWallack R. Functional status and quality of life in chronic obstructive pulmonary disease. Am J Med 2006; 119(10 Suppl 1):32-37.

7. Manini TM, Everhart JE, Patel KV, Schoeller DA, Colbert LH, Visser M, et al. Daily activity energy expenditure and mortality among older adults. JAMA 2006;296(2):171-179.

8. Ward DS, Evenson KR, Vaughn A, Rodgers AB, Troiano RP. Accelerometer use in physical activity: best practices and research recommendations. Med Sci Sports Exerc 2005;37(11 Suppl):S582-S588.

9. ATS Committee on Proficiency Standards for Clinical Pulmonary Function Laboratories. ATS statement: guidelines for the six-minute walk test. Am J Respir Crit Care Med 2002;166(1):111-117.

10. Steele BG, Holt L, Belza B, Ferris S, Lakshminaryan S, Buchner DM. Quantitating physical activity in COPD using a triaxial accelerometer. Chest 2000;117(5):1359-1367.

11. Belza B, Steele BG, Hunziker J, Lakshminaryan S, Holt L, Buchner DM. Correlates of physical activity in chronic obstructive pulmonary disease. Nurs Res 2001;50(4):195-202.

12. Pitta F, Troosters T, Spruit MA, Probst VS, Decramer M, Gosselink R. Characteristics of physical activities in daily life in chronic obstructive pulmonary disease. Am J Respir Crit Care Med 2005;171(9): 972-977.

13. Celli BR, Rassulo J, Make BJ. Dyssynchronous breathing during arm but not leg exercise in patients with chronic airflow obstruction. N Engl J Med 1986;314(23):1485-1490.

14. Castro AA, Porto EF, Feltrim MI, Jardim JR. Asynchrony and hyperinflation in patients with chronic obstructive pulmonary disease during two types of upper limbs exercise. Arch Bronconeumol 2013; 49(6):241-248.

15. de Souza GF, Castro AA, Velloso M, Silva CR, Jardim JR. Lactic acid levels in patients with chronic obstructive pulmonary disease accomplishing unsupported arm exercises. Chron Respir Dis 2010; $7(2): 75-82$.
16. Skumlien S, Hagelund T, Bjørtuft O, Ryg MS. A field test of functional status as performance of activities of daily living in COPD patients. Respir Med 2006;100(2):316-323.

17. Lareau SC, Meek PM, Roos PJ. Development and testing of the modified version of the pulmonary functional status and dyspnea questionnaire (PFSDQ-M). Heart Lung 1998;27(3):159-168.

18. Garrod R, Bestall JC, Paul EA, Wedzicha JA, Jones PW. Development and validation of a standardized measure of activity of daily living in patients with severe COPD: the London Chest Activity of Daily Living scale (LCADL). Respir Med 2000;94(6):589-596.

19. Tufanin A, Souza GF, Tisi GR, Tufik S, de Mello MT, Nascimento OA, Jardim JR. Cardiac, ventilatory, and metabolic adjustments in chronic obstructive pulmonary disease patients during the performance of Glittre activities of daily living test. Chron Respir Dis 2014;11(4):247-255.

20. Karloh M, Karsten M, Pissaia FV, de Araujo CL, Mayer AF. Physiological responses to the Glittre-ADL test in patients with chronic obstructive pulmonary disease. J Rehabil Med 2014;46(1):88-94.

21. Rabe KF, Hurd S, Anzueto A, Barnes PJ, Buist SA, Calverley P, et al. Global strategy for the diagnosis, management, and prevention of chronic obstructive pulmonary disease: GOLD executive summary. Am J Respir Crit Care Med 2007;176(6):532-555.

22. Lerario MC, Sachs A, Lazaretti-Castro M, Saraiva LG, Jardim JR. Body composition in patients with chronic obstructive pulmonary disease: which method to use in clinical practice? Br J Nutr 2006; 96(1):86-92.

23. American Thoracic Society. Standardization of spirometry: 1994 update. Am J Respir Crit Care Med 1995;152(3):1107-1136.

24. Wasserman K, Hansen, JE, Sue DY, Whipp, BJ, Casaburi, R. Principles of Exercise Testing and Interpretation. Philadelphia: Lea \& Fabger; 1994:67.

25. American Thoracic Society, American College of Chest Physicians. ATS/ACCP statement on cardiopulmonary exercise testing. Am J Respir Crit Care Med 2003;167(2):211-277.

26. Browner WS, Newman TB, Hulley SB. Estimating sample size and power: applications and examples. In: Hulley SB, Cummings SR, Browner WS, Grady D, Newman TB, editors. Designing clinical research. Philadelphia: Lippincott Williams \& Wilkins; 2007:65-94.

27. Brown CD, Benditt JO, Sciurba FC, Lee SM, Criner GJ, Mosenifar $\mathrm{Z}$, et al. Exercise testing in severe emphysema: association with quality of life and lung function. COPD 2008;5(2):117-124.

28. Pitta F, Takaki MY, Oliveira NH, Sant'anna TJ, Fontana AD, Kovelis $\mathrm{D}$, et al. Relationship between pulmonary function and physical activity in daily life in patients with COPD. Respir Med 2008;102(8): 1203-1207.

29. Vaes AW, Wouters EF, Franssen FM, Uszko-Lencer NH, Stakenborg $\mathrm{KH}$, Westra M, et al. Task-related oxygen uptake during domestic activities of daily life in patients with COPD and healthy elderly subjects. Chest 2011;140(4):970-979.

30. Castro AA, Porto EF, Iamonti VC, de Souza GF, Nascimento OA, Jardim JR. Oxygen and ventilatory output during several activities of daily living performed by COPD patients stratified according to disease severity. PLoS One 2013;8(11):e79727.

31. Cutaia M, Brehm R, Cohen M. The relationship of the BODE index to oxygen saturation during daily activities in patients with chronic obstructive pulmonary disease. Lung 2011;189(4):269-277.

32. Andrianopoulos V, Franssen FM, Peeters JP, Ubachs TJ, Bukari H, Groenen M, et al. Exercise-induced oxygen desaturation in COPD patients without resting hypoxemia. Respir Physiol Neurobiol 2014; 190:40-46.

33. Casanova C, Cote C, Marin JM, Pinto-Plata V, de Torres JP, Aguirre-Jaime A, et al. Distance and oxygen desaturation during the 6-min walk test as predictors of long-term mortality in patients with COPD. Chest 2008;134(4):746-752. 


\section{Physiologic Requirements of Glittre ADL Test in COPD}

34. Golpe R, Pérez-de-Llano LA, Méndez-Marote L, Veres-Racamonde A. Prognostic value of walk distance, work, oxygen saturation, and dyspnea during 6-minute walk test in COPD patients. Respir Care 2013;58(8):1329-1334.

35. Fotheringham I, Meakin G, Punekar YS, Riley JH, Cockle SM, Singh SJ. Comparison of laboratory- and field-based exercise tests for COPD: a systematic review. Int J Chron Obstruct Pulmon Dis 2015;10:625-643.

36. Takeda K, Kawasaki Y, Yoshida K, Nishida Y, Harada T, Yamaguchi $\mathrm{K}$, et al. The 6-minute pegboard and ring test is correlated with upper extremity activity of daily living in chronic obstructive pulmonary disease. Int J Chron Obstruct Pulmon Dis 2013;8:347-351. 